\title{
Ultrastructural features on the oral cavity floor (tongue, sublingual caruncle) of the Egyptian water buffalo (Bubalus bubalis): gross, histology and scanning electron microscope
}

\author{
F.A. Farrag1', S.F. Mahmoud², M.A. Kassab³, A. Hassan1', F. Abdelmohdy³, M. Shukry4, \\ M.M.A. Abumandour ${ }^{5}$ (D), M. Fayed ${ }^{1}$ \\ ${ }^{1}$ Department of Anatomy and Embryology, Faculty of Veterinary Medicine, Kafrelsheikh University, Kafrelsheikh, Egypt \\ ${ }^{2}$ Department of Biotechnology, College of Science, Taif University, Taif, Saudi Arabia \\ ${ }^{3}$ Department of Cytology and Histology, Faculty of Veterinary Medicine, Kafrelsheikh University, Kafrelsheikh, Egypt \\ ${ }^{4}$ Department of Physiology, Faculty of Veterinary Medicine, Kafrelsheikh University, Kafrelsheikh, Egypt \\ ${ }^{5}$ Department of Anatomy and Embryology, Faculty of Veterinary Medicine, Alexandria University, Alexandria, Egypt
}

[Received: 18 March 2021; Accepted: 13 May 2021; Early publication date: 14 June 2021]

Background: The present work was focused on the evaluation of morphological characteristics of the lingual caruncles and tongue with its papillae of Egyptian water buffalo (Bubalus bubalis) using gross examination, light and scanning electron microscopy.

Materials and methods: The ventral surface of the sublingual caruncle carried a small opening of the duct of both monostomatic and mandibular salivary gland. The lingual mucosa of dorsal, lateral border and, to some extent, of ventral surface of apex had lingual papillae (filiform, fungiform), while the lingual mucosa of the lingual body especially at torus linguae had conical papillae, but circumvallate papillae observed at the caudal part of body and root. The dorsal surface of the apex and body carried numerous long, thread-like, with blunt apex, caudally directed filiform papillae that covered with keratinised scales without secondary papillae. Results: The degree of keratinisation classified filiform papillae into rostral part of high keratinisation and caudal of less keratinisation. Conical papillary surface carried exfoliated epithelium with longitudinal groove on its rostral surface and carried secondary papillae. Fungiform papillae were scattered among filiform papillae on the dorsal and ventral surface of the apex and its convex surface had exfoliated keratinised epithelium. Circumvallate papillae were surrounded by circular deep groove bordered by vallum that carried small secondary papillae that ended into the primary groove. Taste buds of circumvallate papillae opened in the lateral lining epithelium facing the groove.

Conclusions: Von Ebner's glands were observed in computed tomography under papillae especially toward the groove and their ducts open into the base of the groove. (Folia Morphol 2022; 81, 3: 650-662)

Key words: lingual caruncles, tongue, lingual papillae, Egyptian water buffalo, histology, scanning electron microscope (SEM)

Address for correspondence: Prof. M. Abumandour, Department of Anatomy and Embryology, Faculty of Veterinary Medicine, Alexandria University, Alexandria, Egypt, Post Box: 22785, tel: +20 1000322937, fax: +20 452960450, e-mail: m.abumandour@yahoo.com or M.abumandour@alexu.edu.eg

This article is available in open access under Creative Common Attribution-Non-Commercial-No Derivatives 4.0 International (CC BY-NC-ND 4.0) license, allowing to download articles and share them with others as long as they credit the authors and the publisher, but without permission to change them in any way or use them commercially. 


\section{INTRODUCTION}

Egyptian water buffalo Bubalus bubalis (Linnaeus, 1758) subspecies was classified under Bubalus bubalis species, Bubalus genus, Bovidae family, Artiodactyla suborder, Ruminantia order. The Egyptian water buffalo is the most important domestic animal and their number reached 2.5 million [25] in Egypt. The Egyptian water buffalo feed mainly on the green grasses, plants, and other roughage materials with the help of large lips, and elongated protrusible tongue to collect the food materials [38, 39].

The tongue was the most important organ that was modified with characteristic feeding tendencies, behaviour, and various types of food particles that could be accessed; moreover, the lingual structure was modified to play different abilities, for example, feeding input, control, and ingestion of nutrition molecules [3]. The morphological appearance, prevalence, orientation, and structure of lingual papillae were modified in accordance with the nutritional requirements, the types of nutritional particles accessible, and the various environmental conditions [3]. Most previously published anatomical articles concerned on the tongue and its papillae of the domestic animal species $[12,15,18,20,28,32,35,37,49]$ but there were rare data on the Egyptian water buffalo (Bubalus bubalis) from Egypt.

The available data about the sublingual caruncle and sublingual floor of the domestic animals including the Egyptian water buffalo (Bubalus bubalis) were scanty. The current work was conducted to give a full morphological characterisation of the tongue with its papillae, sublingual caruncle, and the sublingual floor of the Egyptian water buffalo (Bubalus bubalis) using the gross, scanning electron microscope (SEM), and histological techniques to describe the relation of our findings with the feeding mechanism of Egyptian water buffalo (Bubalus bubalis). Then, the obtained findings were compared with those reported in the formerly published articles on the ruminant and other domesticated animal species.

\section{MATERIALS AND METHODS}

\section{Sample's collection}

Twelve heads from the normal adult Egyptian water buffalo (Bubalus bubalis) of both sexes were collected from the local slaughterhouse in Kafrelsheikh Governate, Egypt. The samples were collected directly after slaughtering. The present investigation was prepared according to the guidelines for the using and caring of the laboratory animals and animal ethics and welfare in the Faculty of Veterinary Medicine, Alexandria University and according to the Egyptian laws.

\section{Gross morphology observations}

The tongue, sublingual caruncle, and sublingual floor were collected from four Egyptian water buffalo heads of both sexes, were prepared to demonstrate the gross morphology of the tongue, sublingual caruncle, and sublingual floor. Then, the collected samples were fixed in $10 \%$ formalin. The gross morphological images were examined and photographed by a digital camera (Cannon IXY 325, Japan). The anatomical terms followed the [46].

\section{For histological and histochemistry studies}

The tongue, sublingual caruncle, and sublingual floor from four heads of Egyptian water buffalo (Bubalus bubalis), were used in the histological techniques in the fresh state according to Suvarna et al. [52] to examine under a light microscope. The collected samples (tongue, sublingual caruncle, and sublingual floor) were fixed in $10 \%$ normal buffer formalin. After $24 \mathrm{~h}$, the samples were gently transferred to $70 \%$ alcohol. Then, they were dehydrated in ascending graded series of ethanol. Then, the samples were cleared in xylene and impregnated and embedded in paraffin wax. Sections of 5-7 $\mu \mathrm{m}$ were cut using Leica rotatory microtome (RM 2035) and mounted on glass slides. Paraffin sections were used for conventional staining (haematoxylin and eosin) for general histological examinations [10].

For histochemistry processing, the sections were stained with Periodic Acid-Schiff (PAS) technique (ab150680) to demonstrate the neutral mucin [50], Alcian Blue (AB) at pH of 2.5 (ab150662) for acidic mucin [11, 51], Van Gieson (mixture of picric acid and acid fuchsin) for elastic fibres in connective tissue, trichrome for collage fibres in the connective tissue [42]. The histological techniques and stains were adopted according to Suvarna et al. [52].

\section{For scanning electron microscopy}

Four Egyptian water buffalo (Bubalus bubalis) heads were used to collect the samples (tongue, sublingual caruncle, and sublingual floor) used in the SEM technique $[2,5]$. The collected samples (tongue, sublingual caruncle, and sublingual floor) were fixed at $4^{\circ} \mathrm{C}$ in a solution of fixation formed from: $2 \%$ formaldehyde, $1.25 \%$ glutaraldehyde in 


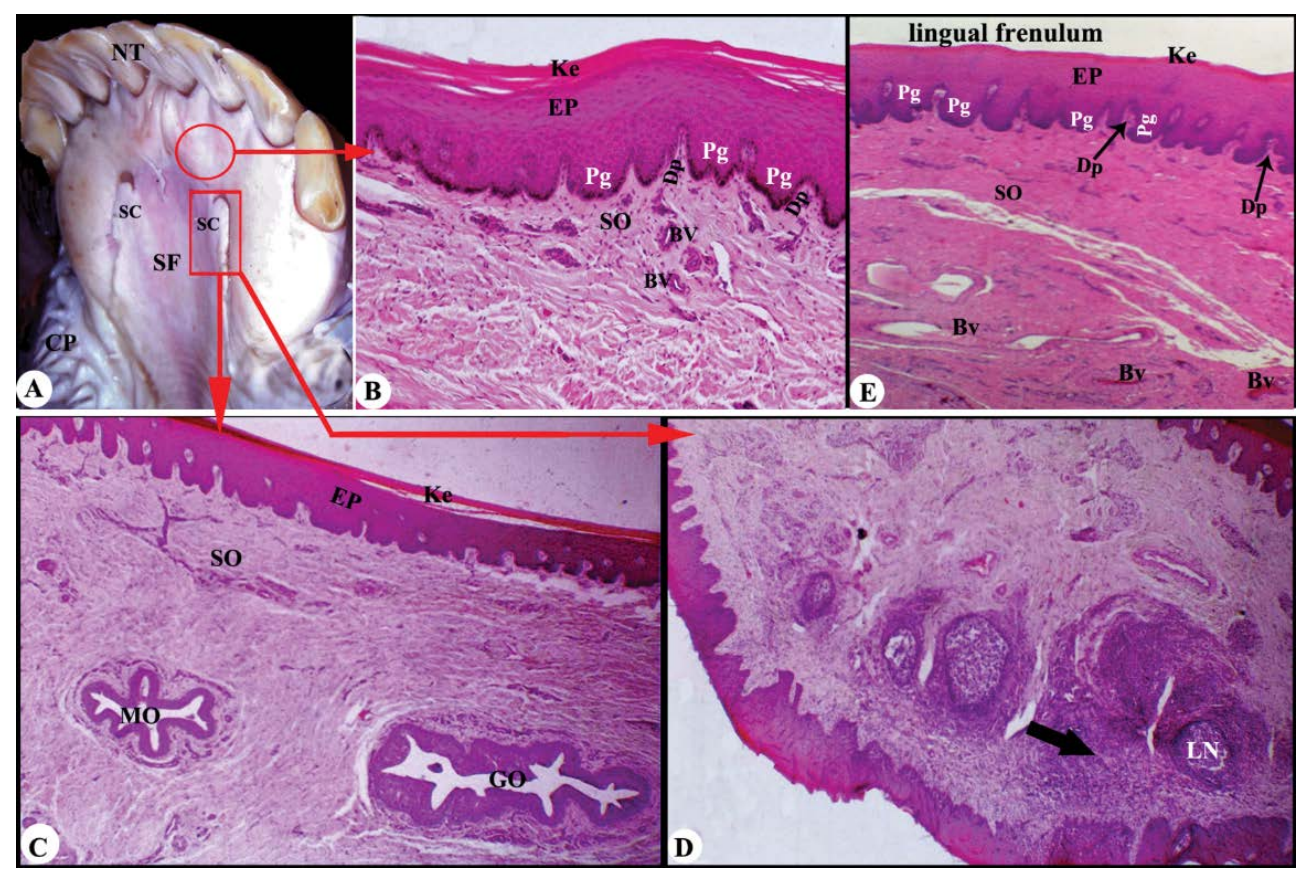

Figure 1. Macroscopic (A) and histological (B-E) images of the sublingual floor of the Egyptian water buffallo. Panel $\mathbf{A}$ to show: incisive teeth (NT), sublingual floor (SF), sublingual caruncles (SC), conical papillae of check (CP). Panels B-D of the sublingual caruncle to show: sligthly keratinised (Ke), stratified squamous epithelium (EP), epidermal peg (Pg), dermal papillae (Dp), submucosa (SO), blood vessls (BV), opening of minor sublingual salivary galnd (MO), opening of minor sublingual salivary galnd (GO), diffuse lymphatic tissue (black arrow), and lymph nodule (Ln). Panel E of lingual frenulum to show: keratinised (Ke), stratified squamous epithelium (EP), epidermal peg (Pg), dermal papillae (Dp), submucosa (SO), blood vessls (BV).

$0.1 \mathrm{M}$ sodium cacodylate buffer, $\mathrm{pH}$ 7.2. Once fixation occurs, the collected samples were washed in $0.1 \mathrm{M}$ sodium cacodylate containing $5 \%$ sucrose, processed through tannic acid. Finally, the lingual samples were dehydrated by using an increasing concentration of ethanol ( 15 min each in $50,70,80,90,95$, and $100 \%$ ethanol). The collected samples were then dried in carbon dioxide and attached to stubs with colloidal carbon and coated with gold palladium in a sputtering device. In the end, the collected samples were examined and photographed with a JEOL SEM operating at $15 \mathrm{kV}$, at the faculty of science, Alexandria University, Egypt.

\section{RESULTS}

Sublingual floor and sublingual caruncle Gross morphological appearance of the sublingual floor and sublingual caruncles

The floor of the oral cavity had the tongue, the sublingual caruncles, and the musculocutaneous wall. The sublingual floor of the oral cavity was crescentic in shape and located under the tongue within the dental arch (Fig. 1A). It was subdivided into two parts: the prefrenular part rostrally and the two sublingual recesses caudally. The prefrenular part was located caudal to the central incisors and extended caudally to the level of frenulum linguae. This part carried two sublingual caruncles (Fig. 1A; SC). The ventral surface of the sublingual caruncle carried a small opening at which opened the duct of both monostoamtic sublingual salivary gland and the mandibular salivary gland.

The frenulum lingua was a mucosal membrane fold connecting the ventral surface of the tongue with the floor of oral cavity. The frenulum lingua was wide, extensive, and single-fold, and it was located caudal to the level of the central incisors. The lateral sublingual recesses (Fig. 2A; SLR) were bounded laterally by the lower cheek teeth and medially by the lateral lingual surface. It was extended from the frenulum linguae rostrally till the level of the pterygomandibular fold caudally. This part had a conical papillae of pointed apex rostrally, while its caudal part was smooth. These conical papillae were arranged in two rows; the upper row had about 15 papillae and the lower one had about 10 papillae only (Fig. $1 A ; C P$ ). 

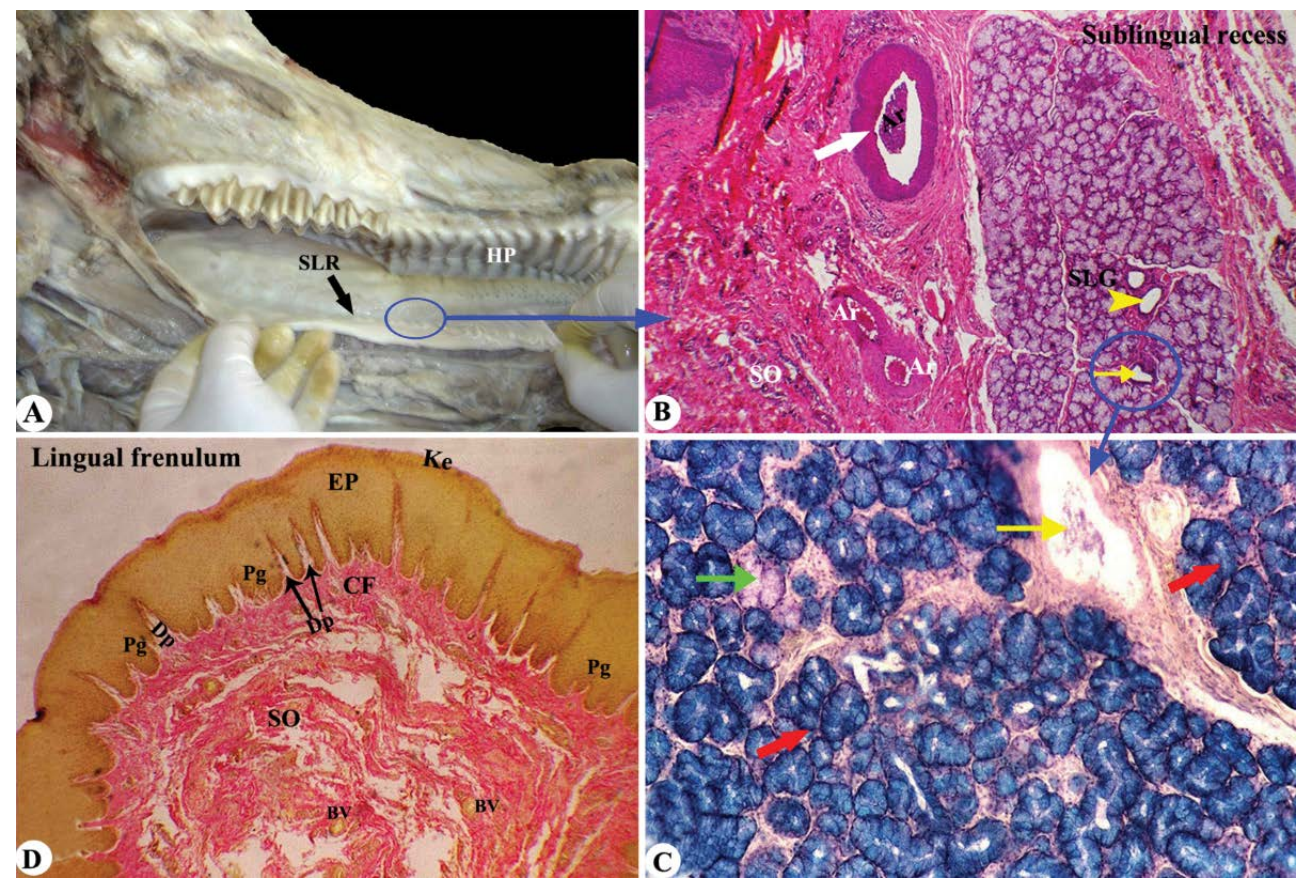

Figure 2. Macroscopic (A) and histological (B-D) images of the sublingual caruncles of the Egyptian water buffallo. Panel $\mathbf{A}$ to show: sublingual recess (SLR), hard palate (HP). Panels B-C to show: artery (Ar), sublingual gland (SLG), submucosa (SO), stained acini (red arrow), unstained acini (green arrows), interlobular duct (yellow arrow), stratiated duct (yeloow arrowheads). Panel $\mathbf{D}$ of lingual frenulum to show: sligthly keratinised (Ke), stratified squamous epithelium (EP), epidermal peg (Pg), dermal papillae (Dp), submucosa (SO), blood vessls (BV).

\section{Histological observations of the sublingual floor and sublingual caruncles}

The floor of oral cavity was lined by stratified squamous keratinised epithelium. Under the epithelium, there was a thick dense irregular connective tissue layer of propria-submucosa of the dermal layer. There were numerous epidermal pegs interdigitated with numerous dermal papillae (Fig. 1B). The sublingual caruncle was lined by stratified squamous keratinised epithelium. Under the epithelium, there was a thick dense irregular connective tissue layer that had two ducts, which opened to the ventral surface of the sublingual caruncle (Fig. 1C). The sublingual caruncle had two surfaces; the dorsal (like that of the floor) and the ventral surface that had aggregations of the lymphocytic nodule's (Fig. 1D). The two ducts in the submucosa of the ventral: one duct of the mandibular and other of monostoamtic sublingual salivary glands (Fig. 1D; MO, GO).

The sublingual recess consisted of stratified squamous keratinized epithelium. The submucosa was highly vascular, highly innervated dense irregular connective tissue contained the sublingual salivary glands. These glands were mucoserous in nature that had positive reaction of PAS and AB stain (Fig. 2C).

The frenulum lingua was lined with stratified squamous keratinised epithelium, and the submucosa consisted of dense irregular connective tissue that highly vascular and innervations. The submucosal layer sends dermal connective tissue papillae to invaginate the mucous membrane and interdigitated with the epidermal pegs. These connective tissue papillae carried secondary papillae (Fig. 1E, 2D).

\section{Tongue}

\section{Gross morphological characters of the tongue}

The tongue occupied the oral cavity proper in the sublingual floor when the upper and lower teeth were close to each other. It reached $36-38 \mathrm{~cm}$ in length (from the lingual root to the lingual apex) and $32 \mathrm{~cm}$ (from the palatoglossal fold to the apex). The free lingual part measured $9-10 \mathrm{~cm}$ in length that formed about $25 \%$ of the total lingual length. The lingual width was wider rostrally than caudally. The tongue is divided into three parts: the apex, the body and the root. The rostral lingual part (apex) was flattened dorsoventrally with two surfaces (dorsal and ventral) and two borders. While the caudal lingual part (body and root) had only the dorsal surface and two lateral borders (Fig. 3A). The dorsal lingual surface had a large, rounded prominence (torus linguae) that was located in front of its deep fossa (fossa linguae) (Fig. 3A, 4A; TL, FL). 


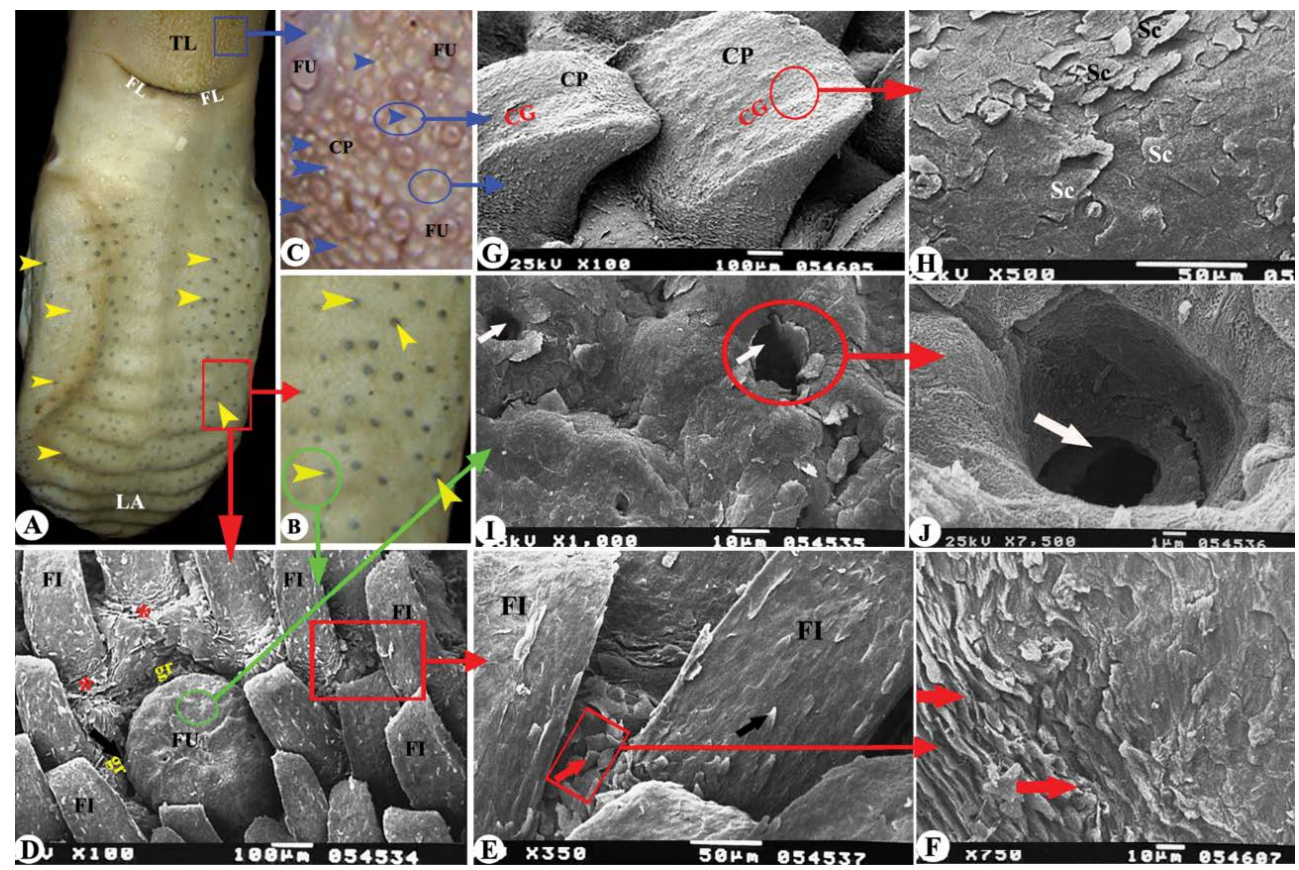

Figure 3. Macroscopic (A-C) and scanning electron microscope (D-J) images of the tongue of the Egyptian water buffallo. Panels A-C to show: lingual apex (LA), torus linguae (TL), fossa lingua (FL), pigmentated fungifrom papillae (yellow arrowheads), non-pigentated fungiform papillae (FU), conical papillae (CP), lentiform papillae (blue arrowheads). Panels D-J to show: filiform papillae (FI) with its depressed origin (red star) and keratinised scales (black arrow), interpapillary space had some exfoliated keratinised epithelia-like filiform papillae surface (red arrow), fungiform papillae (FU) surrounded by circular groove (gr) and carried taste pores on its dorsal surfae (white arrow), conical papillae (CP) with its central groove (CG) and keratinised scales (Sc) on its rostral surface.

The mechanical papillae represented by three papillary types: filiform, conical and lentiform papillae. The filiform papillae were the numerous papillae observed on the lingual mucosa that give the raspy appearance of the buffalo tongue. These papillae were distributed all over the dorsal lingual surface till the beginning of the torus linguae and extended to the lateral border and to some extent on the ventral surface (Fig. 3A). Also, these papillae were observed on the lateral border of the body. The caudally directed conical papillae were restricted only to the torus linguae, especially on its central part. These papillae were of different size; the large ones were observed at the centre of torus linguae and their size decreased at the peripheral of laterally directed areas (Fig. 3A-C; CP). The lentiform papillae of different sizes were observed on the dorsal lingual surface only at the torus linguae (Fig. 3A-C; blue arrowheads).

The gustatory papillae were represented by two papillary types: fungiform and circumvallate papillae. The fungiform papillae were widely distributed all over the dorsum surface and lateral border of the tongue. There were two subtypes of fungiform papillae: the first subtype was the pigmented pa- pillae and concentrated only in the rostral part of the apex and the lateral border of the tongue (Fig. 3A, B; yellow arrowheads). The second subtype was non-pigmented and observed in the caudal part of the apex and torus linguae (Fig. 3C; FU). The circumvallate papillae were observed in the caudal lingual part in front of the palatoglossal fold (Fig. 4A, B; $7 A, B)$. These papillae were arranged in 2-3 irregular rows with papillae of different sizes (Fig. 4B). They were rounded and surrounded by groove, which in turn was surrounded by an elevated part named vallum. There were two papillae with one groove and vallum (Fig. 4B; green ovoid). Their number ranged from 18-24 on each side of the tongue. There was some variation from right to left ranging from 1 to 2 papillae. The foliate papillae were absent and instead there were low mucosal folds in front of the glossopalatine fold.

The smooth lingual root was free from any papillary type but contained the openings of the posterior lingual gland that covered the root surface with their secretions (Fig. 4A). The ventral lingual surface was attached to the sublingual floor by the lingual frenulum; its mucous membrane was somewhat loosely attached to the underlying muscles. 

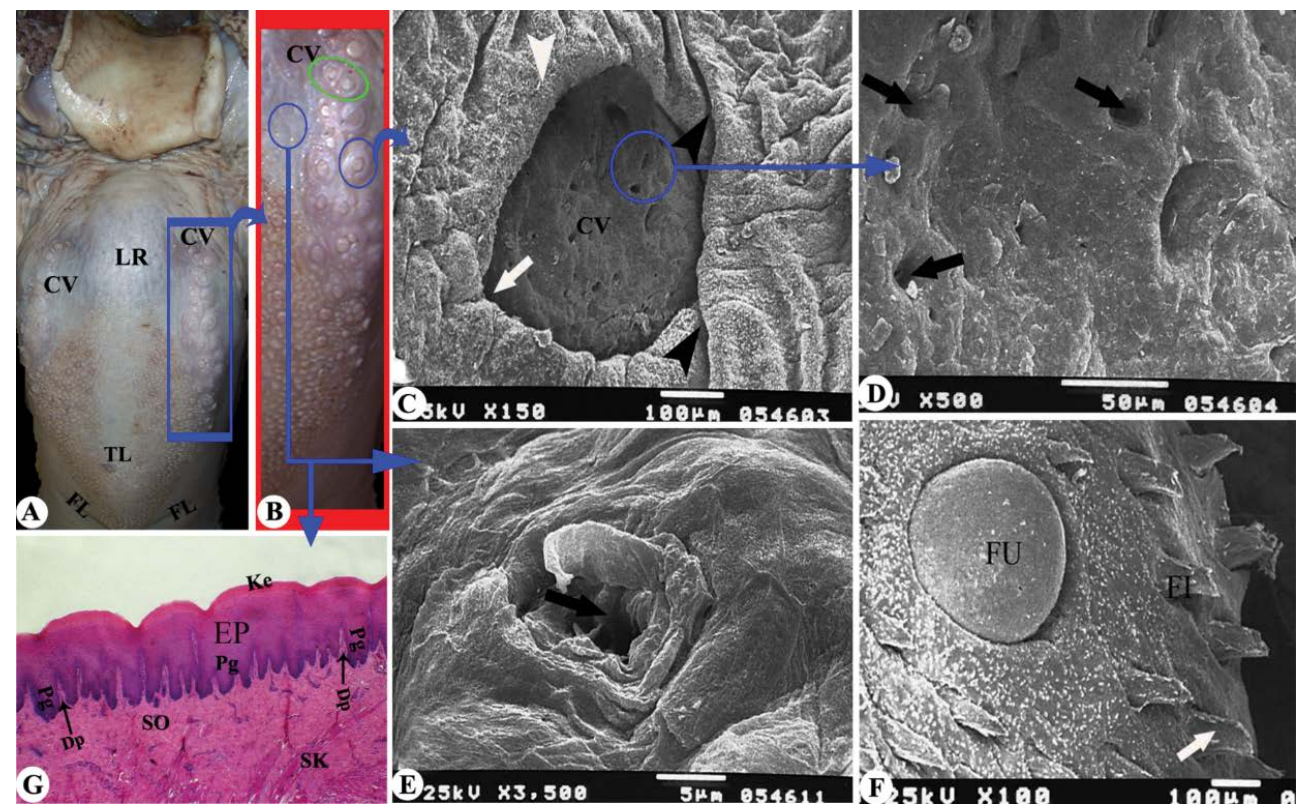

Figure 4. Macroscopic (A, B), scanning electron microscope (C-F) and histological (G) images of the lingual root of the Egyptian water buffallo. Panels A, B to show: lingual root (LR), torus linguae (TL), fossa lingua (FL), circumvallate papillae (CV), two circumvallate papillae surrounded by one vallate (green circle). Panels C-F to show: circumvallate papillae (CV) with numerous small and rounded opening of taste pores (black arrow) and surrounded by circular deep (white arrow) groove that bordered by an elevated ridge named vallum (white arrowheads) that carried small secondary papillae that ended into the primary groove (black arrowheads); FU — fungiform papillae; Panel $\mathbf{G}$ to show: kertainised (Ke) stratified squamous (EP) with numerous epidermal peg ( $\mathrm{Pg}$ ) and dermal papillae (Dp), submucosa (SO), skeletal muscles (SK).

\section{SEM characters of the tongue}

The dorsal lingual surface of the apex and body carried numerous long, band thread-like, with blunt apex, caudally directed filiform papillae (Fig. 3D). The papillary surface was covered with keratinised scales without secondary papillae (Fig. 3E; black arrow). The origin of the filiform papillae appeared as a depressed area (Fig. 3D; red star). The interpapillary space had some exfoliated keratinised epithelia-like filiform papillae surface (Fig. $3 \mathrm{E}$, F; red arrow). The filiform papillae on the ventral surface were less numerous, shorter than that observed on the dorsal surface. In addition, it carried pointed tips with longitudinal groove without secondary papillae.

The surface of the large, broad blunted, short conical papillae was rough and carried exfoliated epithelium (Fig. 3I; CP). The higher magnification showed the presence of longitudinal groove on its rostral surface (Fig. 3G; CG) and the interpapillary surface was exfoliated (Fig. 3G, H; Sc).

The circular or rounded or dome-shaped fungiform papillae were scattered among the filiform papillae on the dorsum of the tongue and the ventral surface of the apex (Figs. 3D, 4F; FU). The convex surface of the fungiform papillae had exfoliated keratinised epithelium and three circular openings of the taste pores (Fig. 3I, J; white arrows).
The rounded circumvallate papillae were surrounded by circular deep groove bordered by an elevated ridge (vallum), as appeared in (Fig. 4C; white arrow). The vallum carried small secondary papillae that ended into the primary groove (Fig. 4C; black arrowheads). The surface of the circumvallate papillae was flattened and raised above the lingual surface and carried numerous small and rounded opening of taste pores (Fig. 4D).

The lingual root had numerous folds and depression. By high magnification, the root revealed irregular shaped opening of posterior lingual glands (Fig. 4E; black arrow). The edges were elevated. The surface of the cells of root carried numerous microridges (Fig. 4E).

\section{Histological characters of the tongue}

The lingual epithelium was followed by a vascular highly innervated dense irregular connective tissue. The lingual core consisted of striated muscular fibres taking different orientations (Figs. 4G, 5-7). The lingual mucosa of the dorsal, lateral border and, to some extent, the ventral surface of the rostral part of the lingual apex had lingual papillae (filiform, and fungiform). While the lingual mucosa of body, especially at the torus linguae, had conical papillae, the circumvallate papillae observed at the caudal part of the lingual body and root. 


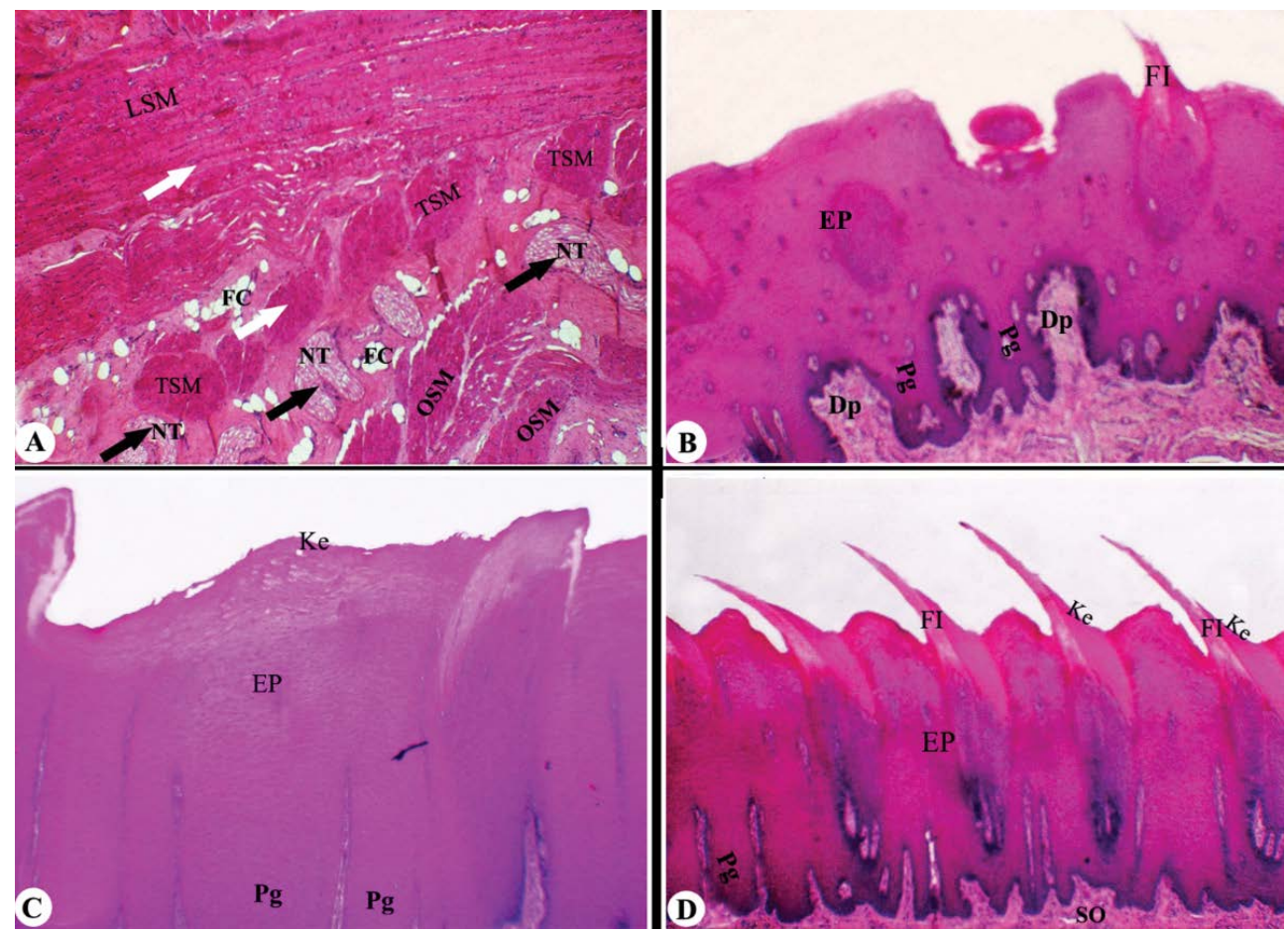

Figure 5. A-D. Histological images of the tongue of the Egyptian water buffalo to show: the longitidinal (LSM), transverse (TSM), and oblique (OSM) lingual muscles, nerve trunk (NT, black arrows), fat cells (FC), filiform papillae (FI), kertainised (Ke), stratified squamous (EP) with numerous epidermal peg $(\mathrm{Pg})$ and dermal papillae (Dp), submucosa (SO).

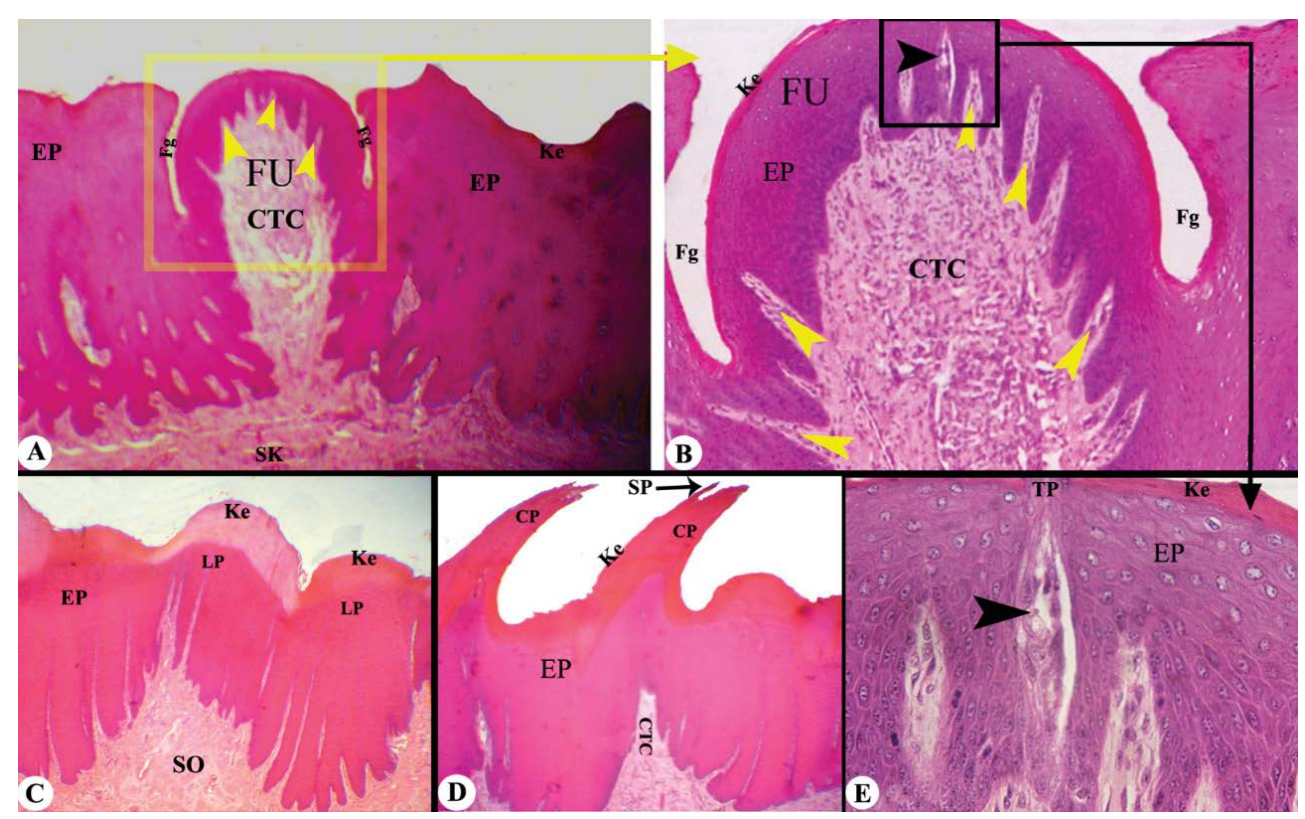

Figure 6. A-E. Histological images of the tongue of the Egyptian water buffalo to show: the fungiform papillae (FU) with taste buds (black arrowheads); taste pore (TP), and connective tisssue core (CTC) with secondary papillae (yellow arrowheads) and surrounded by circular groove $(\mathrm{Fg})$, kertainised (Ke) stratified squamous epithelium (EP), skeletal muscles (SK) and dermal papillae (Dp), submucosa (SO), lentiform papillae (LP), conical papillae (CP), secondary papillae (SP).

The lingual papillae are divided into mechanical and gustatory papillae according to the presence of the taste buds. The mechanical papillae included the filiform, conical, and lentiform papillae, while the gustatory papillae included fungiform and circumvallate papillae (Figs. 5-7). 


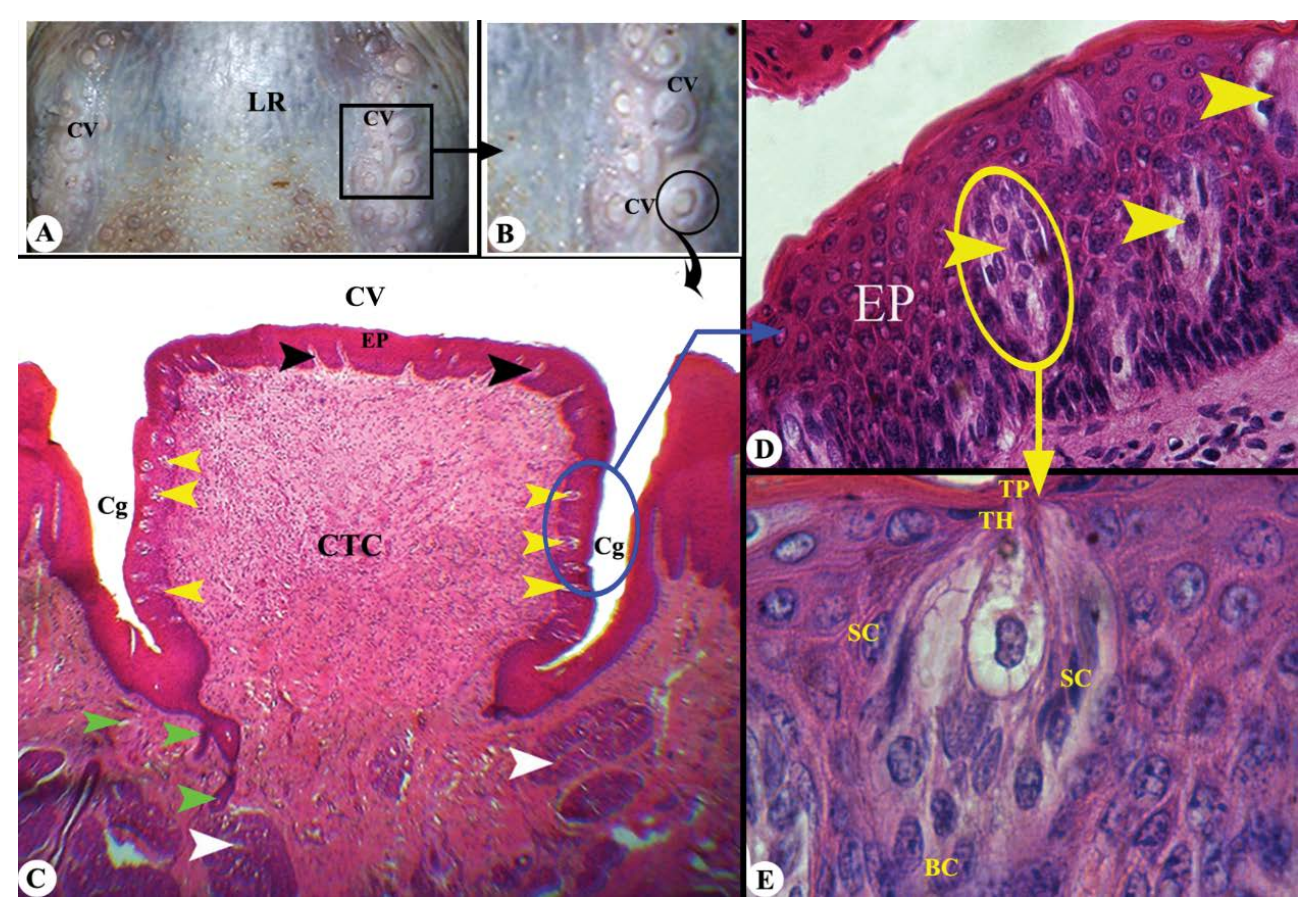

Figure 7. Gross (A, B) and histological (C-E) images of the lingual root of the Egyptian water buffalo to show: the lingual root (LR), circumvallate papillae (CV) with taste buds (yellow arrowheads), taste pore (TP) facing the groove (Cg) and surrounded by sustentacular cells (SC) and basal cells (BC), taste hair (TH), and connective tisssue core (CTC) with secondary papillae (black arrowheads), lobules of von Ebner's glands (white arrowheads) with their ducts (green arrowheads).

The filiform papillae were cornified and had a thread-like appearance with two surfaces: caudal concave and rostral convex surfaces. The keratinised layer differentiated into two parts according to the degree of keratinisation: the rostral part of highly keratinisation and the caudal part less keratinisation papillae (Fig. 5B-D). The conical papillae consisted of highly keratinised stratified squamous epithelium and connective tissue core which did not reach the level surface of epithelium and carried secondary papillae (Fig. 6D).

The fungiform papillae were surrounded by a shallow furrow (Fig. 6A, B, E). It was covered with stratified squamous keratinised epithelium, and its basal cell layers contained pigmented granules in some papillae. The fungiform papillae contained taste buds that opened by taste pore to the dorsal surface (Fig. 6B, E). The connective tissue core was highly vascular dense irregular connective from the secondary papillae originated from the underlying lamina propria (Fig. 6A, B).

The rounded circumvallate papillae were covered by stratified squamous epithelium that was keratinised at its dorsal surface and less keratinised at its lateral border. The taste buds were observed as a lightly stained small areas in the lateral lining epithelium facing the groove (Fig. 7C, D; yellow arrowheads, Cg) that opened by taste pore into the groove with taste hair on the taste duct (Fig. 7D-E; TP, TH). The papillary core consisted of highly vascular and innervated dense irregular connective tissue carrying secondary papillae that penetrated the epithelium lining of the papillae. The lobules of the serous glands (von Ebner's glands) were observed in the connective tissue under the papillae, especially toward the groove, and their ducts opened into the base of the groove (Fig. 7C; white arrowheads).

The lingual root had seromucoid and mucous glands were observed between the skeletal muscular bundles (Fig. 8). Their ducts opened in the dorsal lingual surface. The seromucoid glands were more numerous than mucous ones (Fig. $4 \mathrm{G}$ and 8 ).

\section{DISCUSSION}

The present study was performed to give a complete description of the gross, SEM, histological, and histochemistry characters of the sublingual floor, with their caruncles, and the tongue, with its papillary system, of the Egyptian water buffalo. Similar to some previously published articles $[1,4,18,32,36,54]$, the tongue of the mammalian species is subdivided into three parts: the apex, the body and the root. The cur- 


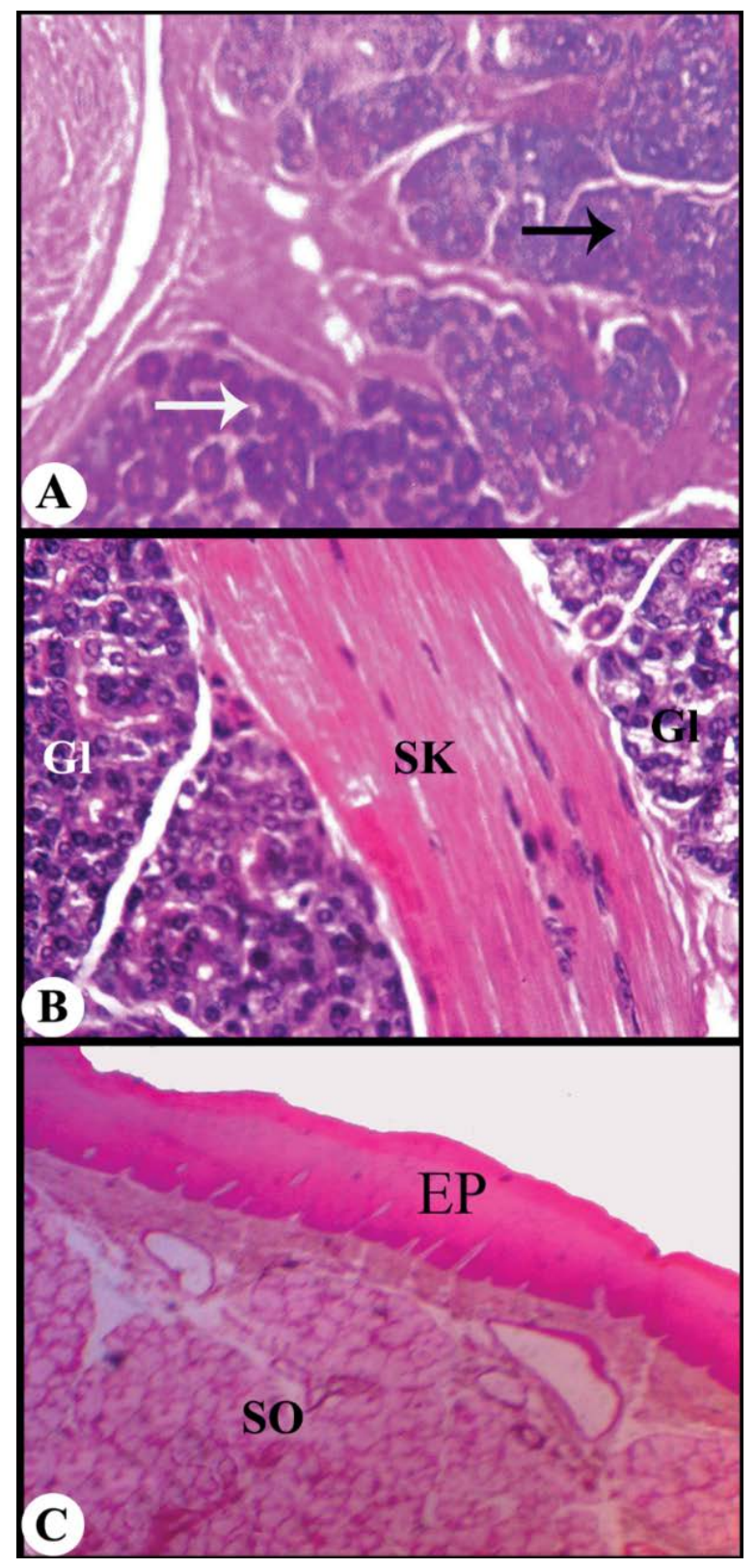

Figure 8. A-C. Histological images of the lingual root of the Egyptian water buffalo to show: sublingual glands (Gl, black arrows), kertanised stratified squamous epithelium (EP), skeletal muscles (SK), submucosa (SO).

rent work described that the flattened dorsoventrally lingual apex had two surfaces (dorsal and ventral) and two borders, while the caudal lingual part (body and root) had only the dorsal surface and two lateral borders. Moreover, El-Bakary and Abumandour [18] classified the ventral lingual surface of the apex into the papillary and non-papillary region by the presence of the projected U-shaped line of fungiform papillae.

The current study observed that the sublingual caruncle was lined with stratified squamous kerati- nised epithelium and the ventral surface of the sublingual caruncle had two ducts: one duct of mandibular and the other of monostoamtic sublingual salivary glands. These observations were similar to those reported by Dyce et al. [16].

The ruminant's species, similar to the herbivorous mammals, are characterised by the presence of the large, rounded prominence named the torus linguae that was bordered rostrally by the deep fossa (named the fossa linguae) on the dorsal lingual surface of the body, as described in the published textbooks about the ruminant's species [16], in addition to the some published articles about the ruminant's species as in Egyptian water buffalo [18, 20], cattle-yak (Bos taurus) [15], reeves' muntjac deer (Muntiacus reevesi) [55], Alpaca (Vicugna pacos) [27]. Also, the characteristic lingual prominence was described in other herbivorous mammalian species as in New Zealand white rabbits [4], Nile grass rat (Arvicanthis niloticus) [43]. Meanwhile, this lingual prominence was absent in the tongue of the carnivorous, omnivorous monkeys and pigs $[22,36]$. Functionally, the presence of the lingual prominence on the dorsal surface of the body was correlated to the herbivorous habits of numerous mammalian species due to this prominence play an important role in the mastication process with the hard palate. The presence of the deep fossa lingua is a characteristic feature of the ruminant species $[15,18,20]$.

The species-variations about the appearance, size, number, distribution, nomenclature, microstructure, and directions of the lingual papillae among different animal species, was related to the feeding habits and the available food particles $[4,15,18-20$, $22,27,36,43,55]$. The current work confirmed the classifications of the lingual papillae into mechanical and gustatory papillae. The current study observed the presence of five types of lingual papillae, three types of mechanical papillae (filiform, conical, and lentiform) and two types of gustatory papillae (fungiform and circumvallate), similar to that described in other ruminant's species such as in Markhoz Goat (Iranian Angora) [26], cattle-yak (Bos taurus) [15] and chital deer (Axis axis) [23]. Meanwhile, the presence of four type - two mechanical (filiform and conical) and two gustatory (fungiform and circumvallate) papillae - was described in other ruminant's species such as Barking deer [6], and Bactrian camel [17], but the four papillae described as one mechanical (filiform) and three gustatory (fungiform, foliate and 
circumvallate) were observed in other herbivorous species such as rabbit $[4]$ and rat $[43,45]$. Functionally, the description of the presence of the different five types of lingual papillae in the current examined Egyptian water buffalo had an important role in the identification and selection of the food particles in the Egyptian farms.

Functionally, the fungiform papillae are classified into three classifications according to function, distribution, and appearance. They are classified according to function into three types: the gustatory fungiform type was described in the currently examined Egyptian water buffalo, similar to that reported by some authors $[4,18,24]$ in rabbit, Egyptian water buffalo, and pampas deer. At the same time, the mixed fungiform papillae (some papillae have taste buds and some do not have them) were described in the horse, buffalo, and cattle $[13,49]$. While, the mechanical fungiform papillae (no taste buds) were described in small ruminants goat [37] and the donkey [41]. The other classification is based on the SEM appearance of the fungiform papillae. The current work observed the presence of the circular or rounded or dome-shaped fungiform papillae among the filiform papillae on the dorsum of the tongue and the ventral surface of the apex, while two shapes - rectangular on the dorsal surface of the apex, and round on the dorsal surface of the body - were described in Egyptian fruit bat [5]. Only one fungiform appearance was described in most mammalian species but with different shape: dome papillae were observed in the raccoon dog and fox [22], round papillae were observed in the tiger and in the pampas deer $[21,24]$, mushroom papillae were observed in the Saanen goat $[37,44]$, fungus papillae in mouse [29].

Circular or rounded or dome-shaped fungiform papillae observed in the present study were scattered among the filiform papillae on the dorsum of the lingual apex and body and, to some extent, on the lateral border and the ventral surface of the apex. Moreover, the presence of the round fungiform papillae was observed among the filiform papillae in the two lateral regions of the dorsal surface of the anterior and middle lingual part, in addition to the papillary region of the ventral surface of the lingual tip and the two lateral borders of the tongue [18] in Egyptian water buffalo (Bubalus bubalis). Generally, the fungiform papillae were scattered among the filiform papillae on the dorsal surface of the apex, as described in some herbivorous ruminants $[6,17$,
$35,37,54]$, but in the deer $[23,24]$ and Mazama species [34], the fungiform papillae distribution were extended to the torus linguae.

The current findings described the presence of the papillary circular groove surrounded the fungiform papillae, similar to that reported in some ruminant species $[4,6,17,18,20,37,54]$, whereas this papillary groove was completely absent in some ruminant species, as described in pampas deer [24].

The lenticular papillae were observed only on the torus linguae. The same findings were described in other ruminants $[17,18]$, whereas the complete absence of the lenticular papillae on the torus linguae was reported in reeves, barking deer, or mazama species $[6,9,34,55]$. Functionally, the presence of the mechanical conical and lenticular papillae had a great role in holding of the food particles during the mastication processes within the oral cavity and help in the movement of masticated food particles toward the pharyngeal cavity [18].

The SEM observations noted that the rough largesized, broad blunted, short conical papillae were restricted only to the torus linguae, especially on its central part, and carried exfoliated epithelium with the presence of longitudinal groove on its rostral surface. The presence of these papillae on the torus linguae was reported in numerous ruminant species $[6,20,24]$. while some authors [18] observed the presence of the large conical papillae on the dorsal lingual surface of root just posteriorly to the torus linguae. However, the complete disappearance of the conical papillae was described in the Bactrian camel (Camelus bactrianus) [17]. Functionally, the presence of the conical papillae was joined with the fixation of the food particles during the mechanical mastication of the green grasses in all ruminant species.

The number of circumvallate papillae differ among mammalian species of the different feeding habits; one type of circumvallate papillae was described by Massoud and Abumandour [43] in Nile grass rat (Arvicanthis niloticus), while two circumvallate papillae were observed in New Zealand white rabbit [4], and horse [32], and three circumvallate papillae were described by Massoud and Abumandour [43] in Egyptian long-eared hedgehog (Hemiechinus auritus), in koala [31], and in Egyptian fruit bat [5]. Moreover, four circumvallate papillae were found in Japanese marten and tiger [21]. Furthermore, the current work agrees with the previous reports on other ruminants species that there were numerous cir- 
cumvallate papillae such as in Egyptian water buffalo [18], cattle [8], reeves' muntjac deer (Muntiacus reevesi) [55], goat [37, 40], lambs [54], and deer [6, 7]. The observation of the prominent papillary groove surrounding the circumvallate papillae were described in the Egyptian water buffalo [18], gazelle [33], goat [35, 37], lamb [54], Alpaca [27] and cattle [14]. The current observation reported that the dorsal surface of the circumvallate papillae was rough and irregular, similar to that noticed by El-Bakary and Abumandour [18] and Emura et al. [22] in Egyptian water buffalo, dog, and fox; however, the smooth dorsal surface of the circumvallate papillae was observed in fox [30].

The degree of keratinisation of the tongue, especially its dorsal surface, is one of the most important lingual adaptations regarding the different feeding mechanisms with available food particles; moreover, this keratinisation extended to the lingual papillae [43]. The filiform papillae had keratinised layer differentiated into two parts according to the degree of keratinisation: the rostral part of high keratinisation and the caudal part less keratinisation papillae. Also the conical papillae had a highly keratinised stratified squamous epithelial layer. Moreover, the fungiform papillae had stratified squamous keratinised epithelium, but the circumvallate papillae had a stratified squamous keratinised layer at its dorsal surface and less keratinized at its lateral border.

The circumvallate taste bud's distribution had some variation among species. The current findings described the presence of numerous taste buds always along the entire length of the papillary wall faced the papillary groove; similar description were reported in camel $[17,47]$, cattle $[48,53]$ and deer [6].

\section{CONCLUSIONS}

The ventral surface of the sublingual caruncle carried a small opening of the duct of both monostoamtic and mandibular salivary gland. The lingual mucosa of the dorsal, lateral border and, to some extent, the ventral surface of apex had lingual papillae (filiform, fungiform). The dorsal surface of the apex and body carried numerous long, thread-like, with blunt apex, caudally directed filiform papillae that were covered with keratinised scales without secondary papillae. The degree of keratinisation classified filiform papillae into rostral part of highly keratinisation and caudal less keratinisation part. Fungiform papillae were scattered among filiform papillae on the dorsal and ventral surface of apex. Taste buds of circumvallate papillae opened in the lateral lining epithelium facing the groove. Von Ebner's glands were observed in computed tomography under papillae, especially toward the groove, and their ducts opened into the base of the groove.

\section{Acknowledgements}

We deeply thank Taif University Researchers Supporting Project number (TURSP-2020/138), Taif University, Taif, Saudi Arabia.

\section{Funding}

Taif University Researchers Supporting Project number (TURSP-2020/138), Taif University, Taif, Saudi Arabia.

Conflict of interest: None declared

\section{REFERENCES}

1. Abd-Elnaeim MMM, Zayed AE, Leiser R. Morphological characteristics of the tongue and its papillae in the donkey (Equus asinus): a light and scanning electron microscopical study. Ann Anat. 2002; 184(5): 473-480, doi: 10.1016/S0940-9602(02)80081-4, indexed in Pubmed: 12392327.

2. Abumandour MMA. Surface ultrastructural (SEM) characteristics of oropharyngeal cavity of house sparrow (Passer domesticus). Anat Sci Int. 2018; 93(3): 384-393, doi: 10.1007/ s12565-017-0426-6, indexed in Pubmed: 29270912.

3. Abumandour MMA. Morphological Comparison of the Filiform Papillae of New Zealand White Rabbits (Oryctolagus cuniculus) as Domestic Mammals and Egyptian Fruit Bat (Rousettus aegyptiacus) as Wild Mammals Using Scanning Electron Microscopic Specimens. Int J Morphol. 2014; 32(4): 1407-1417, doi: 10.4067/s071795022014000400045.

4. Abumandour MMA, El-Bakary RMA. Anatomic reference for morphological and scanning electron microscopic studies of the New Zealand white rabbits tongue (Orycotolagus cuniculus) and their lingual adaptation for feeding habits. J Morphol Sci. 2013; 30(4): 1-12.

5. Abumandour MMA, El-Bakary RMA. Morphological and scanning electron microscopic studies of the tongue of the Egyptian fruit bat (Rousettus aegyptiacus) and their lingual adaptation for its feeding habits. Vet Res Commun. 2013; 37(3): 229-238, doi: 10.1007/s11259-013-9567-9, indexed in Pubmed: 23709139.

6. Adnyane IKM, Zuki AB, Noordin MM, et al. Morphological study of the lingual papillae in the barking deer, Muntiacus muntjak. Anat Histol Embryol. 2011; 40(1): 73-77, doi: 10.1111/j.1439-0264.2010.01041.x, indexed in Pubmed: 21105898.

7. Agungpriyono S, Yamada J, Kitamura N, et al. Morphology of the dorsal lingual papillae in the lesser mouse deer, 
Tragulus javanicus. J Anat. 1995; 187 (Pt 3): 635-640, indexed in Pubmed: 8586562.

8. Asami Y, Asami T, and Ko. Light microscopic and scanning electron microscopic studies on the lingual papillae and stereo structure of their connective tissue cores in cattle. Shigaku (Odontology). 1995; 82: 1223-1244.

9. Atoji Y, Yamamoto Y, Suzuki Y. Morphology of the tongue of a male Formosan serow (Capricornis crispus swinhoei). Anat Histol Embryol. 1998; 27(1): 17-19, doi: 10.1111/j.14390264.1998.tb00150.x, indexed in Pubmed: 9505441.

10. Bancroft JD, Gamble M. Theory and practice of histological techniques. Elsevier Health Sciences, China 2008.

11. Bancroft JD, Cook H, Turner D. Manual of Histological Techniques and Their Diagnostic Application, 2e. 1996.

12. Braekevelt CR. Fine structure of the choriocapillaris, Bruch's membrane and retinal epithelium of the cow. Anat Histol Embryol. 1986; 15(3): 205-214, doi: 10.1111/j.14390264.1986.tb00712.x, indexed in Pubmed: 2947517.

13. Chamorro CA, de Paz P, Sandoval J, et al. Comparative scanning electron-microscopic study of the lingual papillae in two species of domestic mammals (Equus caballus and Bos taurus). 1. Gustatory Papillae. Acta Anat (Basel). 1986; 125(2): 83-87, indexed in Pubmed: 3953255.

14. Chamorro CA, Sandoval J, Fernandez JG, et al. Estudio comparado de las Papilas linguales del Gato (Felis catus) y del Conejo (Oryctolagus cuniculus) mediante el Microscopio electrónico de barrido. Anat Histol Embryol. 2007; 16(1): 37-47, doi: 10.1111/j.1439-0264.1987.tb00722.x.

15. Ding $Y$, Yu S, Shao B. Anatomical and histological characteristic of the tongue and tongue mucosa linguae in the cattle-yak (Bos taurus $\times$ Bos grunniens). Front Biol. 2016; 11(2): 141-148, doi: 10.1007/s11515-016-1393-3.

16. Dyce KM, Sack WO, Wensing CJG. Text book of Veterinary anatomy. W.B. Saunders Company, Philadelphia, London and Toronto 2010.

17. Eerdunchaolu A, Takehana K, Yamamoto E, et al. Characteristics of dorsal lingual papillae of the Bactrian camel (Camelus bactrianus). Anat Histol Embryol. 2001; 30(3): 147-151, indexed in Pubmed: 11447938.

18. El-Bakary NER, Abumandour MMA. Morphological studies of the tongue of the egyptian water buffalo (bubalus bubalis) and their lingual papillae adaptation for its feeding habits. Anat Histol Embryol. 2017; 46(5): 474-486, doi: 10.1111/ahe.12292, indexed in Pubmed: 28833390.

19. El-Mansi A, Al-Kahtani MA, Abumandour M. Comparative phenotypic and structural adaptations of tongue and gastrointestinal tract in two bats having different feeding habits captured from Saudi Arabia: Egyptian fruit bat (Rousettus aegyptiacus) and Egyptian tomb bat (Taphozous perforatus). Zoologischer Anzeiger. 2019; 281: 24-38, doi: 10.1016/j.jcz.2019.05.005.

20. Emura S, El Bakary NER. Morphology of the lingual papillae of Egyptian buffalo (Bubalus bubalis). Okajimas Folia Anat Jpn. 2014; 91(1): 13-17, doi: 10.2535/ofaj.91.13, indexed in Pubmed: 25274404.

21. Emura S, Hayakawa D, Chen $H$, et al. Morphology of the lingual papillae in the tiger. Okajimas Folia Anat Jpn. 2004; 81(2-3): 39-43, doi: 10.2535/ofaj.81.39, indexed in Pubmed: 15455727.

22. Emura S, Okumura T, Chen $\mathrm{H}$, et al. Morphology of the lingual papillae in the raccoon dog and fox. Okajimas Folia
Anat Jpn. 2006; 83(3): 73-76, doi: 10.2535/ofaj.83.73, indexed in Pubmed: 17154050.

23. Erdoğan S, Pérez W. Anatomical and scanning electron microscopic studies of the tongue and lingual papillae in the chital deer (Axis axis,Erxleben 1777). Acta Zoologica. 2013; 95(4): 484-492, doi: 10.1111/azo.12044.

24. Erdoğan S, Pérez W. Anatomical and scanning electron microscopic characteristics of the tongue in the pampas deer (Cervidae: Ozotoceros bezoarticus, Linnaeus 1758). Microsc Res Tech. 2013; 76(10): 1025-1034, doi: 10.1002/ jemt.22263, indexed in Pubmed: 23857640.

25. FAO, Breeds reported by Pakistan: Buffalo. Domestic Animal Diversity Information System, Food and Agriculture Organisation of the United Nations, Rome. 2013.

26. Goodarzi N, Shah Hoseini T. Morphologic and osteometric analysis of the skull of markhoz goat (Iranian angora). Vet Med Int. 2014; 2014: 972682, doi: 10.1155/2014/972682, indexed in Pubmed: 24955281.

27. Goździewska-Harłajczuk K, Klećkowska-Nawrot J, Janeczek $M$, et al. Morphology of the Lingual and Buccal Papillae in Alpaca (Vicugna pacos) - Light and Scanning Electron Microscopy. Anat Histol Embryol. 2015; 44(5): 345-360, doi: 10.1111/ahe.12147, indexed in Pubmed: 25223623.

28. Igbokwe CO. and Okolie C. Morphological study of the lingual papillae at different stages of growth (Prepubertal, Pubertal, Post Pubertal and Adult) of the West African dwarf goat (Capra. Hircus). Int J Morphol. 2009; 27(1): 145-150.

29. Iwasaki Si, Miyata K, Kobayashi K. Comparative studies of the dorsal surface of the tongue in three mammalian species by scanning electron microscopy. Cells Tissues Organs. 2008; 128(2): 140-146, doi: 10.1159/000146330.

30. Jackowiak H, Godynicki S. The scanning electron microscopic study of lingual papillae in the silver fox (Vulpes vulpes fulva, Desmarest, 1820). Ann Anat. 2004; 186(2): 179-183, doi: 10.1016/S0940-9602(04)80037-2, indexed in Pubmed: 15125050.

31. Kobayashi K, Kumakura M, Yoshimura K, et al. Comparative morphological study of the lingual papillae and their connective tissue cores of the koala. Anat Embryol (Berl). 2003; 206(4): 247-254, doi: 10.1007/s00429-002-0296-z, indexed in Pubmed: 12649723.

32. Kobayashi K, Jackowiak H, Frackowiak H, et al. Comparative morphological study on the tongue and lingual papillae of horses (Perissodactyla) and selected ruminantia (Artiodactyla). Ital J Anat Embryol. 2005; 110(2 Suppl 1): 55.

33. Kocak-Harem M, Harem IS, Sari E, et al. Light and Scanning Electron Microscopic Study of the Dorsal Lingual Papillae of the Goitered Gazelle (Gazelle subgutturosa). J Animal Vet Advances. 2011; 10(15): 1906-1913, doi: 10.3923/ javaa.2011.1906.1913.

34. Kokubun H, Esper G, Franciolli A, et al. Estudo histológico e comparativo das papilas linguais dos cervídeos Mazama americana e Mazama gouzoubira por microscopia de luz e eletrônica de varredura. Pesq Vet Bras. 2012; 32(10): 1061-1066, doi: 10.1590/s0100-736x2012001000021.

35. Kumar $P$, Kumar $S$, Singh $Y$. Tongue papillae in goat: a scanning electron-microscopic study. Anat Histol Embryol. 1998; 27(6): 355-357, doi: 10.1111/j.1439-0264.1998. tb00207.x, indexed in Pubmed: 9972641.

36. Kumar S, Bate LA. Scanning electron microscopy of the tongue papillae in the pig (Sus scrofa). Microsc Res Tech. 
2004; 63(5): 253-258, doi: 10.1002/jemt.20036, indexed in Pubmed: 15170754.

37. Kurtul I, Atalgın SH. Scanning electron microscopic study on the structure of the lingual papillae of the Saanen goat. Small Ruminant Res. 2008; 80(1-3): 52-56, doi: 10.1016/j. smallrumres.2008.09.003.

38. Maala CP, Ducusin RJT, Rizori JA. The Gross Anatomy of the Hard Palate and Palatine Printing in Cattle. J Vet Med. 2007; 44(1): 1-7.

39. Maala CP, Ferriol G. Gross anatomy, histology and palatine prints of the hard palate of the Philippine carabao (Bubalus bubalis L. Philippine Agricultural Scientist, Philippines 2002.

40. Mahdy MAA, Abdalla KEH, Mohamed SA, et al. Morphological investigations on the lips and cheeks of the goat (Capra hircus): A scanning electron and light microscopic study. Microsc Res Tech. 2020; 83(9): 1095-1102, doi: 10.1002/jemt.23500, indexed in Pubmed: 32306484.

41. Mahmoud MMAE, Ahmed EZ, Rudolf L, et al. Morphological characteristics of the tongue and its papillae in the donkey (Equus asinus): a light and scanning electron microscopical study. Ann Anat Anat Anz. 2002; 184(5): 473-480, doi: 10.1016/s0940-9602(02)80081-4.

42. Masson P. Some histological methods: trichrome staining and their preliminary technique. J Tech Methods. 1929; 12: 75-90.

43. Massoud D, Abumandour MMA. Descriptive studies on the tongue of two micro-mammals inhabiting the Egyptian fauna; the Nile grass rat (Arvicanthis niloticus) and the Egyptian long-eared hedgehog (Hemiechinus auritus). Microsc Res Tech. 2019; 82(9): 1584-1592, doi: 10.1002/ jemt.23324, indexed in Pubmed: 31225934.

44. Nasr E. Surface morphological structure of the tongue of the hedgehog, Hemiechinusauritus (Insectivora: Erinaceidae). J Am Sci. 2012; 8(4): 580-588.

45. Nasr E, Gamal A, and El. Light and scanning electron microscopic study of the dorsal lingual papillae of the rat Arvicanthis niloticus (Muridae, Rodentia). J Am Sci. 2012; 8(4): 619-627.

46. Nomina AnatomicaVeterinaria N. International Committee on Veterinary Gross Anatomical Nomenclature and author- ized by the general assembly of the world Association of veterinary Anatomist. Knoxville, 3rd Ed. Ghent. Published by the Editorial Committee Hanover (Germany), Ghent (Belgium), Columbia, MO (U.S.A.), Rio de Janeiro (Brazil). 2017.

47. Qayyum MA, Fatani JA, Mohajir AM. Scanning electron microscopic study of the lingual papillae of the one humped camel, Camelus dromedarius. J Anat. 1988; 160: 21-26, indexed in Pubmed: 3253256.

48. Sari EK, Harem MK, Harem IS. Characteristics of dorsal lingual papillae of zavot cattle. J Animal Vet Advances. 2010; 9(1): 123-130, doi: 10.3923/javaa.2010.123.130.

49. Scala G, Mirabella N, Pelagalli GV. [Morphofunctional study of the lingual papillae in cattle (Bos taurus)]. Anat Histol Embryol. 1995; 24(2): 101-105, doi: 10.1111/j.14390264.1995.tb00019.x, indexed in Pubmed: 8588700.

50. Schumacher U, Duku M, Katoh M, et al. Histochemical similarities of mucins produced by Brunner's glands and pyloric glands: A comparative study. Anat Rec A Discov Mol Cell Evol Biol. 2004; 278(2): 540-550, doi: 10.1002/ ar.a.20046, indexed in Pubmed: 15164342.

51. Suvarna KS, Layton C, Bancroft JD. Bancroft's theory and practice of histological techniques. E-Book. Elsevier Health Sciences 2018.

52. Suvarna SK, Layton C, Bancroft JD. Bancroft's Theory and Practice of Histological Techniques, Expert Consult: Online and Print,7: Bancroft's Theory and Practice of Histological Techniques. Elsevier, Churchill Livingstone 2013.

53. Tabata S, Wada A, Kobayashi T, et al. Bovine circumvallate taste buds: taste cell structure and immunoreactivity to alpha-gustducin. Anat Rec A Discov Mol Cell Evol Biol. 2003; 271(1): 217-224, doi: 10.1002/ar.a.10028, indexed in Pubmed: 12552638.

54. Tadjalli M, Pazhoomand R. Tongue papillae in lambs: a scanning electron microscopic study. Small Ruminant Research. 2004; 54(1-2): 157-164, doi: 10.1016/j.smallrumres.2003.11.005.

55. Zheng J, Kobayashi K. Comparative morphological study on the lingual papillae and their connective tissue cores (CTC) in reeves' muntjac deer (Muntiacus reevesi). Ann Anat. 2006; 188(6): 555-564, doi: 10.1016/j. aanat.2006.05.014, indexed in Pubmed: 17140149. 